\title{
Policy in Clinical Practice: Choosing Post-Acute Care in the New Decade
}

\author{
Anil N Makam, MD, MAS²*, David C Grabowski, PhD³
}

${ }^{1}$ Division of Hospital Medicine, San Francisco General Hospital, University of California, San Francisco, San Francisco, California; ${ }^{2} P h i l i p$ R Lee Institute for Health Policy Studies, University of California, San Francisco, San Francisco, California; ${ }^{3}$ Department of Health Care Policy, Harvard Medical School, Boston, Massachusetts.

Nearly half of hospitalized Medicare patients in 2018 were discharged to post-acute care (PAC), accounting for approximately $\$ 60$ billion in annual spending. There are four PAC settings, and these vary in the intensity and complexity of medical, skilled nursing, and rehabilitative services provided; each setting uses a separate payment system. Due to considerable variation in PAC use, with concerns that similar patients can be treated in different PAC settings, the Centers for Medicare \& Medicaid Services (CMS) recently introduced several major policy changes. For home health agencies (HHAs) and skilled nursing facilities (SNFs), CMS implemented new payment models to better align payment with patients' care needs rather than the provision of rehabilitation. For long-term acute care hospitals, CMS will now decrease payment for less medically ill patients. To choose PAC wisely, hospitalists and hospital leaders must understand how these new policies will change where patients can be discharged and the services these patients receive at these PAC settings. Journal of Hospital Medicine 2021;16:171-174. @ 2021 Society of Hospital Medicine

\section{CLINICAL SCENARIO}

A 70-year-old woman with Medicare insurance and a history of mild dementia and chronic bronchiectasis was hospitalized for acute respiratory failure due to influenza. She was treated in the intensive care unit (ICU) for 2 days, received mechanical ventilation, and was subsequently extubated and weaned to high-flow nasal cannula (HFNC) at 8 liters of oxygen per minute and noninvasive ventilation at bedtime. She had otherwise stable cognition and required no other medical or nursing therapies. For recovery, she was referred to a skilled nursing facility (SNF) for respiratory support and rehabilitation but was declined due to HFNC use, noninvasive ventilation, and mild dementia. Instead, she was transferred to a long-term acute care hospital (LTACH) for respiratory support. In the context of major post-acute care (PAC) policy changes, where shouldand could - this patient go to recover after hospitalization?

\section{BACKGROUND AND HISTORY}

In 2018, 44\% of hospitalized patients with fee-for-service Medicare (herein referred to as Medicare) were discharged to PAC, accounting for nearly $\$ 60$ billion in annual Medicare spending. ${ }^{1}$ PAC includes four levels of care-home health agencies (HHAs), SNFs, inpatient rehabilitation facilities (IRFs), and LTACHswhich vary in intensity and complexity of the medical, skilled nursing, and rehabilitative services they provide; use separate

\footnotetext{
*Corresponding Author: Anil N Makam, MD, MAS; Email: Anil.Makam@ucsf.edu; Telephone: 415-206-4875; Twitter: @anilmakam.

Published online first February 17, 2021.
}

Received: September 16, 2020; Revised: November 16, 2020;

Accepted: November 23, 2020

๔ 2021 Society of Hospital Medicine DOI 10.12788/jhm.3577

reimbursement systems; employ different quality metrics; and have different regulatory requirements (Table 1). Because hospitalists care for the majority of these patients and commonly serve in leadership roles for transitions of care and PAC use, PAC policy is important, as it has direct implications on discharge patterns and the quality and nature of patient care after discharge.

HHAs, the most commonly used PAC setting, provide skilled nursing or therapy to homebound beneficiaries. ${ }^{1}$ HHAs were historically reimbursed a standardized 60-day episode payment based on casemix, which was highly dependent on the number of therapy visits provided, with extremely little contribution from nontherapy services, such as skilled nursing and home health aide visits. ${ }^{2}$

SNFs, which comprise nearly half of PAC spending, provide short-term skilled nursing and rehabilitative services following hospitalization. SNFs are reimbursed on a per diem basis by Medicare, with reimbursement historically determined by the intensity of the dominant service furnished to the patienteither nursing, ancillary care (which includes medications, supplies/equipment, and diagnostic testing), or rehabilitation. ${ }^{3}$ Due to strong financial incentives, payment for more than 90\% of SNF days was based solely on rehabilitation therapy furnished, with 33\% of SNF patients receiving ultra-high rehabilitation (>720 minutes/week), ${ }^{3}$ even if it was not considered beneficial or within the patient's goals of care. ${ }^{4}$

IRFs provide intensive rehabilitation to patients who are able to participate in at least 3 hours of multidisciplinary therapy per day. ${ }^{1}$ IRF admissions are paid a bundled rate by Medicare based on the patient's primary reason for rehabilitation, their age, and their level of functioning and cognition.

LTACHs, the most intensive and expensive PAC setting, care for patients with a range of complex hospital-level care needs, including intravenous (IV) infusions, complex wound care, and 
TABLE 1. Definition of Post-Acute Care Settings and New Major Policies Affecting Medicare Payment

\begin{tabular}{|c|c|c|}
\hline Setting & Definition & New Medicare Policy \\
\hline $\mathrm{HHA}$ & $\begin{array}{l}\text { Provides intermittent or part-time ( }<8 \text { hours per day) skilled nursing, therapy, aide services, } \\
\text { and medical social worker services to homebound patients who generally do not leave their } \\
\text { home except for medical appointments, religious services, or other minor outings. HHAs do } \\
\text { not provide meal delivery or preparation, nor do they provide personal care (eg, bathing, } \\
\text { toileting) or home services (eg, cleaning, laundry) if this is the only care provided. }\end{array}$ & $\begin{array}{l}\text { PDGM: A new casemix payment system, PDGM eliminates the number of visits for } \\
\text { rehabilitation therapy as a determinant of HHA payment, and instead considers clinical } \\
\text { diagnosis and other patient factors, including functional impairment, cognitive status, } \\
\text { comorbidities, referral source (community vs institution), and timing (first 30-day period vs } \\
\text { subsequent 30-day periods). }\end{array}$ \\
\hline SNF & $\begin{array}{l}\text { Provides short-term (up to } 100 \text { days) skilled nursing care and rehabilitation therapy to } \\
\text { patients recovering after a qualifying hospitalization of typically } 3 \text { or more days. SNFs do } \\
\text { not provide personal care (eg, bathing, dressing) if this is the only type of care required. } \\
\text { Most SNFs are dually certified as nursing homes, which provide long-term care services (eg, } \\
\text { personal care) that are typically paid by Medicaid but not by Medicare. }\end{array}$ & $\begin{array}{l}\text { PDPM: In a substantial change to the SNF payment system, PDPM eliminates tying payment } \\
\text { to total minutes of rehabilitation therapy and instead considers many aspects of a patient's } \\
\text { condition and care needs, including nursing and ancillary care, such as wound care, } \\
\text { intravenous medication infusions, and respiratory support. }\end{array}$ \\
\hline IRF & $\begin{array}{l}\text { Provides intensive rehabilitation to patients who need at least two therapy modalities and } \\
\text { are able to participate in at least } 3 \text { hours of multidisciplinary therapy a day at least } 5 \text { days a } \\
\text { week. IRFs generally focus on rehabilitation of patients with stroke, spinal cord injury, certain } \\
\text { other neurologic conditions, major trauma, burns, and selected orthopedic conditions. }\end{array}$ & No new policy enacted. \\
\hline LTACH & $\begin{array}{l}\text { Provides care to patients who have extended inpatient care needs following a } \\
\text { hospitalization, with an average length of stay of } 25 \text { or more days. Although specializing in } \\
\text { the care of patients on prolonged mechanical ventilation, LTACHs provide care for a variety } \\
\text { of extended inpatient care needs, including complex wound care, severe infections, and } \\
\text { multiorgan failure. }\end{array}$ & $\begin{array}{l}\text { Site-neutral payment: This policy stipulates full LTACH payment for patients who either had } \\
\text { a preceding intensive care unit stay of } 3 \text { or more days or received prolonged mechanical } \\
\text { ventilation ( } \geq 96 \text { hours) in the LTACH and are not transferred for a rehabilitation or psychiatric } \\
\text { primary diagnosis. LTACH stays not meeting these criteria will receive a substantially reduced } \\
\text { payment. }\end{array}$ \\
\hline
\end{tabular}

Abbreviations: HHA, home health agency; IRF, inpatient rehabilitation facility; LTACH, long-term acute care hospital; PDGM, Patient-Driven Groupings Model; PDPM, Patient Driven Payment Model; SNF, skilled nursing facility.

respiratory support. Since 2002, the only requirements for LTACHs have been to meet Medicare's requirements for hospital accreditation and maintain an average length of stay of 25 days for their population. ${ }^{5}$ LTACH stays are paid a bundled rate by Medicare based on diagnosis.

\section{POLICIES IN CLINICAL PRACTICE}

Due to considerable variation in PAC use, with concerns that similar patients can be treated in different PAC settings, ${ }^{6,7}$ the Centers for Medicare \& Medicaid Services (CMS) recently introduced several major policy changes for HHAs, SNFs, and LTACHs (Table 1 and Table 2). ${ }^{1}$ No major policy changes were made for IRFs.

For HHAs and SNFs, CMS implemented new payment models to better align payment with patients' care needs rather than the provision of rehabilitation therapy. ${ }^{1}$ For SNFs, the Patient Driven Payment Model (PDPM) was implemented October 1, 2019, and for HHAs, the Patient-Driven Groupings Model (PDGM) was implemented January 1, 2020. These policies increase payment for patients who have nursing or ancillary care needs, such as IV medications, wound care, and respiratory support. For example, the per diem payment to SNFs is projected to increase $10 \%$ to $30 \%$ for patients needing dialysis, IV medications, wound care, and respiratory support, such as tracheostomy care. ${ }^{8}$ These policies also increase payment for patients with greater severity and complexity, such as patients with severe cognitive impairment and multimorbidity. Importantly, these policies pay HHAs and SNFs based on patients' clinical needs and not solely based on the amount of rehabilitation therapy delivered, which could increase both the number and complexity of patients that SNFs accept.

To discourage LTACH use by patients who are unlikely to benefit from this level of care, CMS fully implemented the site-neutral payment policy on October 1, 2020 (although it is paused during the coronavirus disease 2019 [COVID-19] pandemic), which substantially decreased payment to LTACHs for patients who either did not have an ICU stay of 3 or more days preceding the transfer or did not receive prolonged mechanical ventilation in the LTACH for 96 or more hours.

\section{COMMENTARY AND RECOMMENDATIONS}

Historically, PAC payment policy has not properly incentivized the appropriate amount of care to be delivered in the appropriate setting. ${ }^{9}$ The recent HHA, SNF, and LTACH policy changes not only shift the discharge of patients across PAC settings, but also change the amount and type of care that occurs at each PAC site (Table 2). The potential benefit of these new policies is that they will help to align the right level of PAC with patients' needs by discouraging inappropriate use and unnecessary services. Under the new HHA and SNF payment models, initial media reports suggest a decline in therapy services has occurred, which could be beneficial if the therapy was excessive and not indicated. 4,10,11 Similarly, LTACHs are experiencing a large decline in admissions as fewer patients meet the new payment criteria. ${ }^{1}$ As with all policy changes, the potential exists for unintended consequences. Because HHAs and SNFs are no longer incentivized to provide therapy, they might withhold the provision of needed rehabilitation therapy. ${ }^{10}$ Furthermore, because payments are based on patient coding by HHA and SNF providers under the new payment models, coding practices may change in order to optimize their payments. Indeed, the PDGM policy for HHAs includes a "behavioral adjustment" to account for anticipated changes in improved documentation by HHAs. Because LTACHs will be less likely to admit patients without prolonged mechanical ventilation or a qualifying ICU stay of 3 or more days, these patients might 
TABLE 2. Incentives for Medicare Beneficiaries Before and After Policy Changes by Post-Acute Care Setting

\begin{tabular}{|c|c|c|c|}
\hline Setting ${ }^{\mathrm{a}}$ & Incentives Before Policy Change & Incentives After Policy Change & $\begin{array}{l}\text { Potential Unintended Consequences Under } \\
\text { New Policy }\end{array}$ \\
\hline \multirow[t]{4}{*}{ HHA } & $\begin{array}{l}\text { Patient selection: Patients who have greater } \\
\text { rehabilitation needs than nursing or ancillary care } \\
\text { needs. }\end{array}$ & \multirow{2}{*}{$\begin{array}{l}\text { Patient selection: Greater incentive to accept patients with } \\
\text { multimorbidity with greater nursing and ancillary care needs; less } \\
\text { incentive for patients with minimal comorbidity burden and those } \\
\text { who only require rehabilitation therapy. Greater incentive to } \\
\text { enroll hospitalized patients than community-dwelling patients. }\end{array}$} & $\begin{array}{l}\text { Patients may receive less rehabilitation therapy because } \\
\text { payment to HHAs is no longer tied to the number of therapy } \\
\text { visits. }\end{array}$ \\
\hline & \multirow{2}{*}{$\begin{array}{l}\text { Duration of services: } 60 \text { days because HHAs received } \\
\text { standardized payment for all covered services, adjusted } \\
\text { for casemix. }\end{array}$} & & \multirow{3}{*}{$\begin{array}{l}\text { CMS may experience more requests to refer to HHA after } \\
\text { hospitalization rather than from outpatient setting, given } \\
\text { increased payment if referral originates from a hospital. }\end{array}$} \\
\hline & & $\begin{array}{l}\text { Duration of services: Either } 30 \text { or } 60 \text { days. The new policy has } \\
\text { split the } 60 \text {-day episode into two } 30 \text {-day episodes, with more } \\
\text { payment for the first } 30 \text { days because more services are used } \\
\text { during this time period. }\end{array}$ & \\
\hline & $\begin{array}{l}\text { Referral: Emphasized patients' functional impairments } \\
\text { and rehabilitation needs because the number of } \\
\text { rehabilitation therapy visits dictated HHA payment. }\end{array}$ & $\begin{array}{l}\text { Referral: More holistic focus on postdischarge needs, including } \\
\text { nonrehabilitation therapy. }\end{array}$ & \\
\hline \multirow[t]{4}{*}{ SNF } & $\begin{array}{l}\text { Patient selection: Patients who have greater } \\
\text { rehabilitation needs than nursing or ancillary care needs. }\end{array}$ & \multirow{2}{*}{$\begin{array}{l}\text { Patient selection: Greater incentive to accept patients with } \\
\text { multimorbidity with greater nursing and ancillary care needs. } \\
\text { The per diem reimbursement is projected to increase between } \\
10 \% \text { and } 30 \% \text { for patients who require dialysis, intravenous } \\
\text { medications, wound care, and respiratory support, such as } \\
\text { tracheostomy care. There will be less financial incentive to accept } \\
\text { patients with minimal comorbidity burden and those who only } \\
\text { require rehabilitation therapy. }\end{array}$} & \multirow{4}{*}{$\begin{array}{l}\text { Patients may receive less rehabilitation therapy because } \\
\text { payment to SNFs is no longer tied to the number of therapy } \\
\text { minutes. }\end{array}$} \\
\hline & $\begin{array}{l}\text { Duration of services: For SNFs, patients with a qualifying } \\
\text { hospital stay and remaining days in the benefit period } \\
\text { are covered for the first } 20 \text { days, with coinsurance of } \\
\$ 176 \text { per day for days } 21-100 \text {. }\end{array}$ & & \\
\hline & \multirow{2}{*}{$\begin{array}{l}\text { Referral: Emphasized patients' functional impairments } \\
\text { and rehabilitation needs because the amount of } \\
\text { rehabilitation therapy dictated SNF payment. }\end{array}$} & Duration of services: No change. & \\
\hline & & $\begin{array}{l}\text { Referral: More holistic focus on postdischarge needs, including } \\
\text { nonrehabilitation therapy. }\end{array}$ & \\
\hline LTACH & $\begin{array}{l}\text { Patient selection: "Sick-but-stable" patients needing 3-4 } \\
\text { weeks of care that is not too medically complex or costly. }\end{array}$ & $\begin{array}{l}\text { Patient selection: Increased focus on patients needing mechanical } \\
\text { ventilation or who have survived a critical care stay of } 3 \text { or more } \\
\text { days and require 3-4 weeks of hospital-level care. }\end{array}$ & $\begin{array}{l}\text { Patients who have LTACH-level care needs but do not meet } \\
\text { the new payment criteria may be inappropriately referred to } \\
\text { other PAC settings. }\end{array}$ \\
\hline
\end{tabular}

${ }^{a}$ No new major policy changes were made to inpatient rehabilitation facilities.

bIncludes medications, supplies, equipment, and diagnostic testing.

Abbreviations: CMS, Centers for Medicare \& Medicaid Services; HHA, home healthcare agency; LTACH, long-term acute care hospital; PAC, post-acute care; SNF, skilled nursing facility.

remain in the hospital for longer periods of time if they are too sick or their care needs are too complex for other PAC settings. Given these possible unintended consequences, the implications for hospital discharge patterns, PAC access, and quality of care will need to be closely monitored, as it is unclear how these PAC policy changes will impact patient care.

In terms of broader payment reform, the four PAC settings are still fragmented, with little effort to unify payment, regulation, and quality across the PAC continuum. As required by the Improving Medicare Post-Acute Care Transformation (IMPACT) Act of 2014, we would encourage the adoption of a unified PAC payment system that spans the four settings, with payments based on patient characteristics and needs rather than site of service. ${ }^{12}$ This type of reform would also harmonize regulation and quality measurement and reward payments across settings. Currently, CMS is standardizing patient assessment data and quality metrics across the four PAC settings. Given the COVID-19 pandemic, the transition to a unified PAC payment system is likely several years away.

\section{WHAT SHOULD I TELL MY PATIENT?}

For our patient who was transferred to an LTACH after referrals to SNFs were denied, PAC options now differ following these major PAC policy reforms, and SNF transfer would be an option. This is because SNFs will receive higher payment for providing respiratory support under the PDPM, and LTACHs will receive considerably lower reimbursement because the patient did not have a qualifying ICU stay or require prolonged mechanical ventilation. Furthermore, hospitals participating in accountable care organizations would achieve greater savings, given that LTACHs cost at least three times as much as SNFs for comparable diagnoses.

Instead of referring this patient to a LTACH, the care team (hospitalist, discharge navigator, and case manager) should inform and educate the patient about discharge options to SNFs for weaning from respiratory support. To help patients and caregivers choose a facility, the discharge planning team should provide data about the quality of SNFs (eg, CMS Star Ratings scores) instead of simply providing a list of names and locations. ${ }^{13,14}$ Discharge planning should start as soon as possible to permit caregivers an opportunity to visit facilities and for the providers to coordinate the transfer as seamlessly as possible.

\section{CONCLUSION}

Recent major PAC policy changes will change where hospitals discharge medically complex patients and the services they will receive at these PAC settings. Historically, reduction in PAC use has been a key source for savings in alternative payment models that encourage value over volume, such as accountable care organizations and episode-based ("bundled") payment models. ${ }^{15}$ We anticipate these PAC policy changes are a step in the right direction to further enable hospitals to achieve value by more closely aligning PAC incentives with patients' needs. 
Disclosures: Dr Makam received travel expenses from the National Association of Long Term Hospitals (NALTH) for an invited presentation in February 2020. Dr Makam has also received a research grant from NALTH. Dr Grabowski received research grants from the National Institute on Aging, the Agency for Healthcare Research and Quality, The Donaghue Foundation, the Warren Alpert Foundation, and the Arnold Foundation. He received personal fees from naviHealth, the Medicare Payment Advisory Commission, Compass Lexecon, Analysis Group, Abt Associates, and the Research Triangle Institute. The authors have no other conflicts of interest to disclose, financial or otherwise.

Funding: Dr Makam was supported by the National Institute on Aging (K23AG052603). The study sponsors had no role in the preparation, review, or approval of this manuscript.

\section{References}

1. Report to the Congress: Medicare Payment Policy. Medicare Payment Advisory Commision; 2020. Accessed February 9, 2021. http://www .medpac.gov/docs/default-source/reports/mar20_entirereport_sec.pdf?s fvrsn $=0$

2. Medicare and Medicaid Programs; CY 2020 Home Health Prospective Payment System Rate Update; Home Health Value-Based Purchasing Model; Home Health Quality Reporting Requirements; and Home Infusion Therapy Requirements. Fed Regist. 2019;84(217):60478-60646. To be codified at 42 CFR Parts 409, 414, 484, and 486. https://www.govinfo.gov/content /pkg/FR-2019-11-08/pdf/2019-24026.pdf

3. Medicare Program; Prospective Payment System and Consolidated Billing for Skilled Nursing Facilities (SNF) Final Rule for FY 2019, SNF Value-Based Purchasing Program, and SNF Quality Reporting Program. Fed Regist. 2018;83(153):39162-39290. To be codified at 42 CFR Parts 411, 413, and 424. https://www.govinfo.gov/content/pkg/FR-2018-08-08/pdf/2018-16570.pdf

4. Weaver C, Mathews AW, McGinty T. How Medicare rewards copious nursing-home therapy. Wall Street Journal. Updated August 16, 2015. Accessed October 13, 2020. https://www.wsj.com/articles/how-medicare-rewards -copious-nursing-home-therapy-1439778701

5. Eskildsen MA. Long-term acute care: a review of the literature. J Am Geriatr Soc. 2007;55(5):775-779. https://doi.org/10.1111/j.1532-5415.2007.01162.x
6. Newhouse JP, Garber AM. Geographic variation in health care spending in the United States: insights from an Institute of Medicine report. JAMA. 2013;310(12):1227-1228. https://doi.org/10.1001/jama.2013.278139

7. Makam AN, Nguyen OK, Xuan L, Miller ME, Goodwin JS, Halm EA. Factors associated with variation in long-term acute care hospital vs skilled nursing facility use among hospitalized older adults. JAMA Intern Med. 2018;178(3):399-405. https://doi.org/10.1001/jamainternmed.2017.8467

8. Skilled Nursing Facilities Payment Models Research Technical Report. Acumen; 2017. https://www.cms.gov/Medicare/Medicare-Fee-for -Service-Payment/SNFPPS/Downloads/SNF_Payment_Models_Research _Technical_Report201704.pdf

9. Ackerly DC, Grabowski DC. Post-acute care reform-beyond the ACA. New Engl J Med. 2014;370(8):689-691. https://doi.org/10.1056/NEJMp1315350

10. Span P. A change in Medicare has therapists alarmed. New York Times. November 29, 2019. Accessed September 16, 2020. https://www.nytimes. com/2019/11/29/health/new-old-age-medicare-physical-therapy.html

11. Graham J. Why home health care is suddenly harder to come by for Medicare patients. Kaiser Health News (KHN). February 3, 2020. Accessed September 16, 2020. https://khn.org/news/why-home-health-care-is -suddenly-harder-to-come-by-for-medicare-patients/

12. Medicare Payment Advisory Commision. Implementing a unified payment system for post-acute care. In: Report to the Congress: Medicare and the Health Care Delivery System. Medicare Payment Advisory Commision; 2017:chap 1. http://www.medpac.gov/docs/default-source/reports/jun17 ch1.pdf?sfursn=0

13. Nazir A, Little MO, Arling GW. More than just location: helping patients and families select an appropriate skilled nursing facility. Ann Long Term Care: Clin Care Aging. 2014;22(11):30-34. Published online August 12, 2014. https://www.managedhealthcareconnect.com/articles/more-just -location-helping-patients-and-families-select-appropriate-skilled-nursing

14. Tyler DA, Gadbois EA, McHugh JP, Shield RR, Winblad U, Mor V. Patients are not given quality-of-care data about skilled nursing facilities when discharged from hospitals. Health Aff (Millwood). 2017;36(8):1385-1391. https://doi.org/10.1377/hlthaff.2017.0155

15. Barnett ML, Mehrotra A, Grabowski DC. Postacute care-the piggy bank for savings in alternative payment models? New Engl J Med. 2019;381(4): 302-303. https://doi.org/10.1056/NEJMp1901896

Journal of Hospital Medicine Leading By Exam 